\title{
Siting Sudaneseness: Territory, Practice, and Identity in Aragi
}

\author{
Bjorn Curley
}

\section{Abstract}

The word "aragi" refers to a type of crude, distilled alcoholic drink brewed by Sudanese people throughout Sudan and bordering countries as well as in smaller Sudanese communities around the world. To the people of Sudan residing in neighbouring Egypt, however, aragi is more than a simple beverage; it is a cultural artifact whose value lies in its material and empirical embeddedness in social practice. This paper investigates the symbolic role that aragi plays in the production of identity among displaced Sudanese living in Cairo, Egypt. For Sudanese migrants in Egypt, aragi acts as a signifier, both linguistic and cultural, of their identity. This migrant identity is inhabited and generated through various practices involving aragi, within the social, spatial, and material spheres. In Egypt, Sudanese identity and aragi (as a cultural object) are ethnographically observed to be contextually and semiotically bound through their mutual signification in the word "aragi." Herein, I will explore how the word "aragi" reflects and articulates social domains of inclusion and exclusion within an identity construed as distinctly Sudanese.

\section{Abstract}

L' «aragi» est une sorte boisson alcoolisée distillée grossière, brassée par des personnes soudanaises à travers le Soudan et les pays limitrophes ainsi que dans des petites communautés soudanaises dans le monde entier. Pour les Soudanais résidant en Égypte voisine, cependant, l'aragi est plus qu'une simple boisson, c'est un artefact culturel dont la valeur réside dans son ancrage matériel et empirique dans la pratique sociale. Le présent article examine le rôle symbolique que joue l'aragi dans la production de l'identité chez les Soudanais déplacés qui vivent au Caire. Pour les migrants soudanais en Égypte, l'aragi est un signifiant, à la fois linguistique et culturel, de leur identité. Cette identité migrante est habitée et générée par les différentes pratiques impliquant l'aragi dans les sphères sociales, spatiales et matérielles. En Égypte, on observe ethnographiquement la liaison contextuelle et sémiotique entre l'identité soudanaise et l'aragi (en tant qu'objet culturel) à travers leur signification mutuelle dans le mot «aragi.» L'auteur étudie ici comment le mot "aragi» reflète et exprime des domaines sociaux d'inclusion et d'exclusion au sein d'une identité considérée comme nettement soudanaise.

\section{Introduction}

Dotted throughout Cairo, Egypt are places where "aragi," a crude form of distilled alcohol indigenous to Sudan, can be found. These places are typically rented flats in which aragi is produced, sold, and consumed. Aragi is familiar, and often dear, to people from throughout Sudan. Egyptians, on the other hand, tend to regard aragi, which they call "arag," with disinterest if not disdain. Many Egyptians describe aragi as they would describe something alien, distasteful, or immoral. Furthermore, Egyptian authorities view aragi with suspicion and, occasionally, hostility. After all, aragi is unlicensed alcohol and is thus illegal in Egypt.

Indeed, as the Sudanese of Cairo well know, brewing aragi in Egypt is not without its dangers. The production, sale, and consumption of this beverage are therefore treated by aragi's patrons with great discretion and respect. ${ }^{1}$

The anthropological significance of aragi lies in its artifactual quality as a cultural object. As a material form empirically embedded in Sudanese social life, the role of aragi can be ethnographically invoked and observed to articulate something about displaced Sudanese migrants in Cairo. ${ }^{2}$ My assertion in this paper is that aragi is more than "just" an alcoholic substance: I intend to "reveal what a material, which is so mundane as to be taken for granted, is actually doing in social terms,"3 as Miller puts it. 
To this effect, the semiotic character of the word "aragi" in the context of Sudanese social life in Egypt is instrumental. Upon analytical breakdown, the word "aragi," when articulated in this context, will be seen to correspond metaphorically to actual social and spatial demarcations. This correspondence effectively signifies in the referent, aragi, a potent symbol situated at the core of the activities and practices taking place within those particular demarcations. Therein, aragi takes on a symbolic role in the process of identity construction through social practice. (The work of F. Barth's Ethnic Groups and Boundaries provides a formative framework on the relationship between symbolism, identity, and practice relevant to the remainder of this discussion .) ${ }^{4}$ The precise significance of "aragi" will be demonstrated in the following pages.

While the theoretical range of this paper is wide, its scope is not carved out to accommodate a substantive theoretical inquiry into any particular area, nor a critical examination of subjects such as "identity" or "displacement." Ultimately, this paper draws loosely on various broad notions, exemplifying the suggestion that there are observable correlations between semiotics, symbolism, space, and identity at the most mundane levels of social experience.

On a general level, this paper explores the significance of material objects as symbols, and their relation to processes of identity formation under explicit circumstances. Specifically, it seeks to illustrate the value of the former exercise by revealing the symbolic role of a particular cultural object in the construction of identity among displaced Sudanese in Egypt.

\section{Ethnographic Context}

This paper is the result of a thesis written towards the completion of a Master of Arts in sociology-anthropology at the American University in Cairo, Egypt, in 2002. Titled "Aragi: An Ethnography of Sudanese Displacement," the thesis was a comparative study of aragi's role in the social, cultural, and economic experiences of Sudanese communities in Egypt and Uganda. These communities are largely comprised of those forcibly displaced by Sudan's long civil war of 1983-2005, but also include some opportunistic social and economic migrants. Ethnographic research was conducted utilizing a long list of "research participants," which included Sudanese migrants and refugees, various members of host communities, non-governmental organizations (NGOs), and government officials. This list was broken down with as much parity as possible along lines of age, gender, religion, and ethnicity.

The study placed heavy emphasis on the significance of aragi in relation to identity construction, as ethnographically observed in Cairo and Uganda. Following the completion of the thesis, further fieldwork was carried out in Cairo, adding depth to the original investigation. Subsequent concerted fieldwork was conducted in 2005 with the help of Sudanese research assistants and my Sudanese research partners (some of whom were insiders to the aragi scene and were granted greater access into Cairo's physical spaces of aragi that I, as a non-Sudanese person, would have been). Information was gathered through participant observation in the form of open-ended interviews using a set of predetermined questions, which were memorized and recorded as "head notes" in order to minimize the perception of an ethnographic "gaze." However, the research-based intent of the exercise was always made explicit and participant-consent was granted upon the researchers' assurance of total anonymity.

In accordance with the established terms of ethnographic practice, aragi is considered an ethnographic "site," which I paraphrase to be a location, social group, practice, object, or process that serves as a thematic anchor from which to develop social analysis. As such, aragi is immediately situated because it is always part of a social context. Social life cannot be conveyed without context. But, nor can context alone, however interesting it is, be conveyed for its own sake (lest it negate its own meaning as a word). Context is something that only appears, only comes into being, through the object of focus that it accommodates. The context that surfaces during a study of aragi is an effect of focusing on aragi. It is my conscious intention to regard this context through aragi as the very "site" to seize for this study as aragi is only anthropologically interesting insofar as it has social context. And if aragi can only be registered as something socially interesting through its context, then it is indeed the social context that is of implicit interest. Thus aragi and its context become meaningful through one another.

Situating aragi as a "site" contextualized in Sudanese displacement sets the framework in which aragi may be observed analytically as a symbol of identity and whereby we arrive ultimately, as outlined in the following pages, at a suggestion of "Sudaneseness."

A final caveat: Though this paper is grounded in an ethnographic methodology, it is not an ethnography in the strict sense. Rather, it occupies a realm in which anthropological inquiry takes on a slightly removed theoretical view of its ethnographic surroundings. It is this ethno-theoretical zone in which the analytical approach of this paper finds its most suitable framing.

\section{“Andaya"}

The homes of Sudanese aragi brewers in Egypt are improvised drinking places modelled on traditional drinking venues in Sudan and adapted to a state of displacement. 
Aragi is traditionally brewed throughout Sudan, where it is available for consumption in a number of spatial settings. Within Sudan's borders, the homestead is the setting of aragi's production and a place where aragi is also consumed in limited amounts by circles of close kin and friends. Public drinking places, known in Sudanese Arabic as andaya, are the settings in which aragi is openly traded, sold, and consumed. In an andaya, aragi is found alongside a variety of other traditional beverages, such as maize and millet beers and honey wine. These andaya are organized as small markets or huts and generate a great deal of social activity. ${ }^{5}$

Homes of Sudanese aragi brewers in Cairo have, in some ways, inherited the role of the andaya in Sudan; they have become semi-commercial spaces open only to a community of select Sudanese patrons. Cairo's makeshift andayas reflect the wide ethnic diversity of Sudan at large as the clientele of the migrants' home breweries serve a variety of ethnic and endemic contexts with regard to particular regions and localities in Sudan.

The partakers of aragi in Cairo usually do not use the term "andaya" to refer to the place where they purchase, drink, or produce aragi. Rather, the drinking spot is typically referred to by the name of the woman doing the brewing or by the slang term "tromba," denoting a "refilling" station. For analytical purposes within this paper, I will use the word "andaya" to refer to the Cairo flats where aragi is brewed due to these spaces' somewhat "public" redolence as Sudanese drinking establishments.

In Cairo, not everyone is granted admittance to the spaces of aragi. Access to the andaya operates on the basis of a network of "insiders," which socially unfolds to include people existing along coordinates of combined trust and interest. Someone wanting to drink aragi is initially accepted only through his or her association with a known acquaintance. Since this association is generated through a common interest in drinking aragi, and takes time to demonstrate, the network of trust is gradually forged between select Sudanese people, who effectively take on something of a status as member over time. As a result, the clientage of Sudanese aragi is invariably composed, almost without exception, of Sudanese consumers rather than Egyptians. More precisely, this consumer base is comprised of mostly male drinkers from Sudan, whose common affiliation with aragi transcends the differences in their cultural, ethnic, regional, and linguistic allegiances within Sudan. Southerners and northerners, even traditional adversaries such as ethnic Dinkas and Bagarras, are found meeting in aragi. This point is particularly significant given the longstanding animosity that has been so dramatically characterized by regional differences during the Sudanese civil war, preceding it, and today.
Admission to Cairo's spaces of aragi represents diversity because its mode of inclusion is determined by one's part in an aragi-based network. The criterion for acceptance into this network is formed in relation to aragi before and above all else. As such, aragi gathers together a wide array of Sudanese people on the broad basis of a shared Sudaneseness in aragi, and it is precisely this common attribute that delimits its social boundaries.

This grid of overall inclusion, extracted from an assembled network of Sudanese people living in Cairo, markedly contrasts with the categorical exclusion that defines Egyptians' relationship to aragi. This general barring of Egyptians from the domain of aragi is the result of three factors. The first factor is created by default, as most Egyptians, including those who have Sudanese acquaintances, are apparently unaware of the presence of aragi in the community or are simply not interested in drinking this type of alcohol. Secondly, Egyptian authorities contribute to the exclusivity of aragi by making that same exclusivity a core condition of aragi's survival. Licensed alcoholic beverages are widely available in Egypt while aragi, being produced informally, is illegal. However, this circumstance is often ignored by authorities so long as aragi's presence is not deemed to have an effect upon Egyptian social life. In practice, this means that aragi cannot be removed from the confines of the Sudanese flats in which it is brewed. As such, authorities are actively suspicious of Egyptians who drink aragi as these individuals would be, effectively, acting as liaisons between a perceived immorality carried out in the realm of aragi and the surrounding Egyptian community. Third, and finally, Cairo's brewers are weary of the presence of aragi as it represents fertile ground for tension in a host community that is predominantly Muslim. Aragi's brewers are conscious of the fact that the production and consumption of aragi may be reported by anyone unhappy with it, including Sudanese neighbours intending to threaten or incriminate the Sudanese tenant. Until fairly recently, there was still another cause for the strict concealment of aragi: its illegality could attract the attention of Egyptian authorities to the more precarious issue of residence status. ${ }^{6}$ In Cairo, this furtive hold on aragi is marked by a stringent spatial practice that socially excludes Egyptians from access to the spaces of aragi.

What we observe in aragi, then, is its representation of the spatial demarcation of social domains of inclusion and exclusion.

\section{The Semiotic Landscape}

That aragi acts as a mode of differentiation which produces social and spatial inscriptions of inclusion and exclusion is significant as the meaning generated by this circumstance is 
observable in terms of contrasts. In essence, this implicates aragi in a semiotic process in which its meaning as a cultural form emerges in a relational sense, as semiotics would have it. ${ }^{7}$ Aragi articulates meaning from an underlying set of social relationships instantiated in its particular context in Sudanese displacement and defines the boundaries that mark and delimit spheres of difference. It outlines the spatial delineation of inner and outer domains of social signification directly etched from that distinct context.

Henrietta Moore remarks that the field of semiotics is especially valuable for the study of space, around which this discussion shall build, because it establishes a series of homologies of spatial, symbolic, and social orders where "the material and mental are joined together in the notion of boundary, constituted through the ways in which humans perceive, build and classify their social and natural worlds." ${ }^{\text {S }}$ Subjecting aragi to basic semiotic analysis, viewing it as a social and linguistic sign, prepares the way for a semiological investigation of its spatial dimensions and social meaning as a situated cultural form. Culler, evoking Saussure, explains,

The task of the semiologist in dealing with clothing, commercial objects, pastimes, and all these other social entities, is to make explicit the implicit meanings they seem to bear and to reconstruct the system of connotations on which these meanings are based. ${ }^{9}$

In the context of Sudanese displacement in Egypt, aragi persistently communicates something about identity with a contextual insistence on Sudaneseness by marking it off from Egyptians through exclusion to the domain of the andaya, while including all Sudanese within it. "Sudaneseness" is the result of an identity obliged to emerge from the semiotic and contextual bounds of aragi. I regard this identity to be both constituted by, and constitutive of, aragi as a symbol.

Indeed, this semiotic attribute of aragi is accurately situated to apprehend its contextual and cultural relevance because of its precise alignment along boundaries of social activity empirically discernible among displaced Sudanese in Cairo. That is, the semiotic and contextual dimensions of aragi form something of a nexus through which the cultural terms of Otherness are established; dimensions that, in a state of Sudanese displacement, tightly correspond and align symbolically in aragi to potentiate identity. Specifically, in aragi the semiotic and the contextual intersect and interact to simultaneously reflect and inform identity formation emergent in terms of Sudaneseness.

Using Moore's above mentioned homologies, the following pages shall demonstrate that aragi may be viewed as a site in which sign, space, and social practice combine to generate symbolic meaning emergent and observable in the form of Sudanese identity.

"Aragi"

The word "aragi" is an Arabic word pronounced in a way particular to Sudan, as opposed to other pronunciations for the same substance around the Middle East, such as "arag," "raki," or "arake." It literally means "sweat" or "my sweat," alluding to the condensation that results from the heating stage of the distillation process. Aragi is made from any number of fermented substances, including such as dates, cassava, or maize. The word "aragi" is used in both the Arabic of the north and in the Juba Arabic dialect, the latter being the lingua franca for the many languages spoken in the south. Thus, the word "aragi" is used throughout Sudan at a level corresponding to the political delineations of Sudan as a nation-state. Though a person of Bari ethnicity will use the word "yawa-naruak" and an ethnic Nuer speaker will use the word "kong-macher" to signify the same type of alcohol, upon meeting the two would signify the drink using the word "aragi."

While the word "aragi," as used throughout Sudan, has the characteristic of a trans-local signifier, there is no particular character, quality, or value that it signifies beyond plainly and simply that distilled substance known in local terms as "aragi" by a northerner, "yawa-naruak" by a Bari, and "kong-macher" by a Nuer.

\section{The Signifier}

When the Sudanese Arabic word "aragi" contrasts with another word for the same referent in any language of Sudan other than Sudanese Arabic then, by virtue of that contrast, the word "aragi" becomes discernible as a signifier other than a signifier of local distinction. Once aragi comprehensively transcends the diverse grounds of these local signifiers by crossing the political frontiers of Sudan as a nation-state, it then comes to adopt signification in terms of which a northerner and members of distinct groups, such as Shilluk or Kakwa, have in common: that they each come from different places within Sudan while they all find themselves outside of Sudan. Once the word "aragi" is capable of enacting signification in an interaction between a Dinka, a Zande, and a northerner in a way that simultaneously contrasts with the Egyptian sig nifier "arag," it emerges as a sign that signifies, in addition to the drink itself, an invocation, a notion, a trace of overall "Sudanesness." In other words, what "aragi" signifies is above all else inside of Sudan while also being distinct from that which is outside of Sudan.

The signifiers "aragi," "arag," and, say, "mau-chol" each refer to the same general type of alcoholic substance within 
the respective linguistic sign systems in which they operate. That which is signified, the actual material substance, remains indifferent to the multiple linguistic and dialectical differences that refer to it, until their differentiation attains significance and meaning through their encounter in a mutual, single referent arising as one from those multiple language systems. Hence, as a Sudanese Arabic signifier, "aragi" assumes something Sudanese about its object by contrasting simultaneously with other semiotic systems signifying the same thing-those of the Egyptian and of the local Sudanese.

\section{The Signified "Thing"}

The way in which aragi is situated in Sudanese social relations in Cairo thus imbues it with a quality of Sudaneseness. The link between "aragi" as a Sudanese signifier, formally differing from other signifiers for the same referent, and the meaning of aragi as a "Sudanese thing," occurs in a contextual correlation between the signifier and its object, in which the differences between signifiers correspondingly inform the actual differences signified through the object. This contextual injunction represents a shift from form to meaning, marking the fusion of sign and context in aragi, and clearing the way for an analytical shift in emphasis from the semiotics of the signifier "aragi" to the semiology of "aragi the thing."

To reiterate, there is nothing definitively Sudanese about aragi until it is displaced from Sudan where, semiotically speaking, the signifier "aragi" is simultaneously opposed to both the Egyptian signifier on one front, and all local Sudanese signifiers on the other. This semiotic differentiation stands as an idiom for the social juxtaposition of "Sudanese" to "Egyptian" on the one hand, and of "Dinka," "Shilluk," and so on, on the other. In other words, the differentiation inscribed by the word "aragi" as a Sudanese signifier carries a direct bounding correlation to Sudanese social life as defined by the confines of the andaya, the actual setting of the aragi it signifies. The semiotic posture, then, of the word "aragi," and the empirical social modes of differentiation formed around the thing that it signifies, correlate and overlap in a way that assumes a near uniform delineation in social life. And thus emerges a union, a blend, of sign and context, a semiology whereby "aragi" invokes the social articulation of the thing it signifies. And, in my point of view, it is through this convergence that aragi takes on the role of symbol.

\section{Identity}

Moore writes that "the meaning of symbols is given by their operationalisation in different contexts, rather than merely by their position in an abstract system of differences ... Sign systems are thus firmly situated both in social practices and in wider social strategies." ${ }^{10}$ Aragi acts as a symbol of identity by operating at the level of the "Sudanese," referentially aligned with the frontiers of Sudan, in its nation-state construct, as the bounding metaphor for its many peoples displaced beyond that Sudan. And, in this sense, aragi is a symbolic territory of a composite, discrete, and national "Sudaneseness," diacritically annexed through its particular manner of differentiation in enjoined semiotic and contextual space. In its particular social and spatial fulfillment in the andaya, then, this symbolic territory attains the actual, tangible, and concrete grounds on which symbolism and space merge in the expression of a Sudanese identity.

\section{Territory}

Aragi, then, becomes the locus of a social activity that literally "takes place" inside the andaya. This activity is centrifugally bound to aragi such that the meaning it produces emerges with respect to the socio-spatial boundaries that circumscribe it. That Egyptians are shut out of the andaya, and an array of Sudanese identities are encompassed within it, means that what is left in place of other identities is a space synonymously identifiable with Sudaneseness. Amid the general breakdown in the isomorphism of space, place, and culture as experienced by Sudanese people displaced to Cairo, the significance of the andaya lies in its response to this de-territorialized identity in which space is detached from local places in Sudan. The andaya represents a re-territorialization of identity by Sudanese people who, having crossed their borders, create new territorial relationships and ultimately new transnational spaces. The andaya is an example of "how people form meaningful relationships with the locales they occupy, how they attach meaning to space, and transform 'space' into 'place."'11

Aragi is an example of, as Miller puts it, "objects that can demonstrably be seen to matter to people, even where those same people do not make any claim."12 The state of alterity, or "Otherness," for Sudanese people in Egypt is definable by a realm of being in relation to the host community in which, generally speaking, Sudanese people are recognized neither as Egyptian nor in terms of their various ethnicities from inside their country of origin. According to the Sudanese interviewed in Cairo, they are typically addressed as "Sudani" or "Africani," if not by more blatantly derogatory terminology such as "iswid" (black) or "abd" (slave). As such, they hover under a shell of identity imposed essentially by default. By contrast, what is palpable in the andaya is the way in which this contour of alterity settles onto a canopy of "Sudaneseness" at large. Indeed, aragi demonstrates the capacity for appropriating this alteric construction and transforming it into a tenable and tractable identity 
by defining and inhabiting it in social and spatial terms, and in turn generating that identity through the practices surrounding it within the andaya. The emergent Sudanese identity is, perhaps, not the conscious outcome of these practices but, rather, results from them and in turn informs them. The bounded practices of the andaya are the bounding property of this Sudanese identity.

\section{Practice}

"The meaning of any spatial order is not intrinsic, but must be invoked through spatial practice." 13 The process of inhabiting a space of alterity is inevitably woven to practice and is therefore empirically observable as such. I identify three forms of such social practice within the andaya that underlie the formation of Sudanese identity. These are: "restricted commoditization," "commensality," and "identity recursivity."

\section{Restricted commoditization}

Aragi has both use value and exchange value and is thus, by conventional definitions, a "commodity." In Sudan, aragi is sometimes limited to social value in which its use is confined to ritual and ceremonial contexts. But its economic value, once sold or exchanged, is rarely limited by factors other than supply and demand and tends, when possible, to transcend cultural, ethnic, and tribal bounds. ${ }^{14}$ In Egypt refugees are prohibited from employment. This restriction applied to all Sudanese migrants until the relatively recent "Four Freedoms Agreement" which, inter alia, granted the right to employment to Sudanese non-refugees. Nevertheless, according to my own ethnographic observations, many Sudanese migrants' incomes are still obtained largely through informal means. As recently as 2009 a study of the Sudanese community by the Centre for Migration and Refugee Studies at the American University in Cairo stated:

The majority [of Sudanese] were either self-employed or employed in the private sector. Domestic work, including cleaning, cooking and babysitting, was a common occupation as well as other low-wage/low-skilled jobs in private companies, such as driving and security. Some of the participants reported that they were self-employed in the handicraft and hospitality fields. ${ }^{15}$

While not explicitly indicated here, aragi production and sale would fall under the "self-employed" category and come within the "hospitality" field, as would other service-based illicit activities such as freelance prostitution.

In Cairo, aragi is especially valued by brewers, primarily because it can be exchanged for money, the most reliable mode of exchange in an urban environment. However, no matter how profitable aragi is, its ability to be distributed among the widest possible range of customers is, as we have seen, affected by circumstances of displacement in Cairo. The economic character of aragi in Cairo is an example of what Appadurai calls "commodity candidacy," which refers to, "the standards and criteria (symbolic, classificatory, and moral) that define the exchangeability of things in any particular social and historical context." 16 The exchangeability of aragi in Egypt is limited to selective criteria of insider and outsider distinctions. This means that a margin of profit is forgone in lieu of concerns about safety and the protocols of acquaintanceship. This, in effect, resists the logic of commoditization by closing out spheres of exchange. That Egyptians are excluded from entering into exchanges with aragi represents an opportunity cost. But though this misplaced economic opportunity is imposed through precarious circumstances in which aragi circulates, it becomes an example of what Kopytoff calls "commodity singularization," meaning that excessive commoditization is seen as essentially anti-cultural and that it necessarily takes on limits in the sense that "commoditization homogenizes value, while the essence of culture is discrimination." 17 The discrimination that informs the social composition of the andaya is the result of, and operational in, a process of singularization wherein aragi is a restricted commodity, confined to a very narrow sphere of exchange. The cultural disposition to which aragi becomes singularized is expressed in terms of the Sudaneseness that defines that sphere of exchange in opposition to an economic sphere involving Egyptians. Aragi is de-commoditized down to its Sudaneseness and no further-it does not discriminate between, is not singularized to, internal identities comprising Sudaneseness as a whole. Hence, we are able to observe that the behaviour of aragi as a commodity produces both profit and identity in one and the same operation.

\section{Commensality}

Commensality is "the state or act of eating together, one of the fundamental acts of social solidarity." 18 It concerns the "body" in its biological, spatial, and social forms. Embodied space, explain Low and Lawrence-Zunige, is "the location where human experience and consciousness take on material and spatial form." ${ }^{.19}$ In the andaya, aragi represents a point in which biological and social bodies merge in a single "embodied space."

Aragi is incorporated, through drink, into the space of each individual body. Each body is in turn connected to the other through the sharing of aragi within a shared space. In the social context of aragi this domain of sharing is premised on, and restricted to, those bodies being Sudanese bodies, 
whether they call themselves Dinka, Zande, Shilluk, etc. . The space shared and defined by aragi thus becomes, in the andaya, a Sudanese place in which "Sudaneseness" becomes embodied as one more index of identity. This shared setting draws together a range of discursive practices such as joking, banter, argumentation, political and historical discussions, leisure talk, and story-telling that are channelled into the formation of that identity. It is through commensality that Sudanese identity is perhaps most outstanding, most strongly evident. As Fortes notes,

Nothing so concretely dramatizes acceptance-that is, incorporation in the self-be it of a proffered relationship, or of personal condition, or of conferred role and status, as taking into one's body the item of food or drink chosen to objectify the occasion ... The intangible is thus made tangible-word is made flesh-and therefore assimilable and manageable. ${ }^{20}$

\section{Identity recursivity}

By "recursivity" I mean an action or process whereby identity seems emergent through recourse to antecedent, traditional social practices, at least so perceived. In Sudan, as among the Sudanese of Cairo, aragi contains in its production a socio-economic division between southerners and northerners. Though all Sudanese, members of all parts of the community in Cairo, consume aragi, its production is limited to southerners. This regional distinction is a product of broad cultural distinctions between northerners who are mostly Muslim and who tend to identify themselves with Arab culture, and southerners who are Black Africans and are predominantly Christian or Animist. The absence of aragi production among northerners is attributable to Islamic social norms and cultural attitudes that quite strictly prohibit alcohol and which, according to northern and southern and male and female interviewees, discourages an association between women and alcohol. This latter point, while it certainly merits a lengthy, significant, and interesting inquiry in its own right, remains, however, outside the scope of examination in our present discussion. Suffice it to say that in my observations, these Islamic norms succeed more in preventing women from producing aragi, or any other alcoholic products, than they do in dissuading men from consuming it. Since aragi production, in the meantime, traditionally falls within the more or less autonomous realm of women's domestic activities, it turns out that it is mainly southern women who produce the aragi while the Sudanese community, as a whole, consumes it. This distinction, consequently, sets up a condition in which regional identities have occasion to interact regularly through practices of buying and selling in a reassertion of regional differences that reflect traditional cultural encounters intrinsic to Sudan.
The significance of this distinctive gender-based interaction between southerners specifically and Sudanese in general is that it establishes a routine symbiotic encounter that affixes a familiar regional realm of identity-southernonto the far less tangible notion of "Sudaneseness." Thus the hollow construct of "Sudaneseness" becomes anchored and meaningfully filled out through its recursive link to a localized, southern identity. This ongoing interaction between producers and consumers serves to exercise an experience of Sudanese displacement in terms that are loosely pre-established and contain elements of practice inherent to Sudan itself, thus transforming an otherwise empty and imposed construct into a tenable reference for identity.

\section{Conclusion}

Low and Lawrence-Zuniga point out, "Space can have no meaning apart from practice." 21 Indeed, wherever space is recognizable it is because it is marked off from other spaces through differentiation. In the andaya, social practice activates spatial meaning through which identity becomes inferable. As such, an identity succeeds in becoming defined through its semiotic context, and becomes observable through empirical Sudanese social and spatial practices in aragi. Displaced to Egypt, aragi becomes a joint semiotic and empirical site in which the production and consumption of a common Sudanese drink acts as a process for the production and consumption of a Sudanese identity.

Nevertheless, if this identity belongs to the Sudanese involved in the aragi scene, then it also belongs more or less to the confines of the andaya. How far this national identity seeps from the andaya into the greater community would likely be difficult to know. A Sudanese identity, as a national construct, is not necessarily a notion that can be evinced from Cairo's Sudanese community at large. However, as aragi has shown, there may be signs of it anywhere.

\section{Notes}

1. Fieldwork on this subject was carried out intermittently in Cairo, Egypt, between the summer of 2001 and early 2005, and to a lesser extent it continues to the present.

2. Sudanese people living in Cairo are, in large part, previously forced migrants (rejected asylum seekers, recognized refugees, and political exiles) who have been displaced due to Sudan's long-standing civil war. A 2001-2002 report by Michael Kagan notes that the number of asylum seekers in Egypt had grown so substantially since 1999 as to make Cairo UNHCR's largest office for refugee status determination (RSD) in the world for a period of time; see Michael Kagan, "Assessment of Refugee Status Determination Procedure at UNHCR's Cairo Office, 2001-2002," Forced 
Migration and Refugee Studies Working Paper No.1 (Cairo: American University in Cairo, 2002), 5.

The number of Sudanese forced migrants living in Cairo has been estimated at over 100,000; see C. Moorehead, "Lost in Cairo," New York Review, June 13, 2002. Other estimates for all types of Sudanese migrants combined range between two to four million.

3. D. Miller, "Why Some Things Matter," in Material Cultures: Why Some Things Matter, ed. D. Miller (Chicago: University of Chicago Press, 1998), 9.

4. F. Barth, Ethnic Groups and Boundaries: The Social Organization of Culture Difference (Oslo: Universitetsforlaget, 1969).)

5. B. Curley, "Aragi: An Ethnography of Sudanese Displacement" (master's thesis, American University in Cairo, 2002), 52-3.

6. One of the most enduring problems that Sudanese people in Cairo have faced until fairly recently (and while the bulk of this research was carried out) is that most of them have had illegal residence status, unless recognized as refugees, making them highly vulnerable to arrest and deportation. This has changed since the signing of the Four Freedoms Agreement on June 16, 2004, ratified and in force since September 2005, granting Sudanese and Egyptians the right to work, residency, movement, and ownership, in each other's countries.

7. For a concise introduction to Saussurian linguistics, the essential basis of semiotics, see J. Culler, Saussure (London: Fontana Press, 1976).

8. H. L. Moore, Space, Text and Gender: An Anthropological Study of the Marakwet of Kenya (Cambridge: Cambridge University Press, 1986).

9. Culler, 101.

10. Moore, 3.

11. S. M. Low and D. Lawrence-Zuniga, "Locating Culture," The Anthropology of Space and Place: Locating Culture, ed. S. M. Low and D. Lawrence-Zuniga (Berlin: Blackwell Publishers, 2003), 13.
12. Miller, 13.

13. Moore, 6.

14. Curley, 79-88.

15. Y. Ahmed, The Prospects of Assisted Voluntary Return among the Sudanese Population in Greater Cairo (Cairo: Centre for Migration and Refugee Studies, American University in Cairo, 2009), 32.

16. A. Appadurai, "Introduction: Commodities and the Politics of Value," in The Social Life of Things: Commodities in Cultural Perspective, ed. A. Appadurai (Cambridge: Cambridge University Press, 1986), 14.

17. I. Kopytoff, "The Cultural Biography of Things: Commoditization as Process," in Social Life of Things, 73.

18. C. Seymour-Smith, Macmillan Dictionary of Anthropology (London and Basingstoke: Macmillan, 1986), 44.

19. Low and Lawrence-Zuniga, 2.

20. M. Fortes, "Totem and Taboo," Presidential Address, Proceedings of the Royal Anthropological Institute, 1966, 16.

21. Low and Lawrence-Zuniga, 10.

Bjorn Curley received a Master of Arts in anthropologysociology at the American University in Cairo in 2002. His thesis, entitled "Aragi: An Ethnography of Sudanese Displacement," was a comparative field study of identity formation through social practice among Sudanese refugees and migrants in both Egypt and Uganda. In 2003 he received a postgraduate diploma from the Forced Migration and Refugee Studies Centre in Cairo after studying under Dr. Barbara Harrell-Bond and conducting research on the coping strategies of Ethiopian and Eritrean refugees living in Egypt.

Since 2004, he has worked for the United Nations Refugee Agency in Egypt, Kenya, Sudan, Tanzania, Malaysia, and Iraq. He currently lives in Kuala Lumpur, Malaysia, and continues to be academically active in the fields of anthropology and migration. 